\title{
Keşifsel Veri Analizi Kullanarak Vakum Şarj Test Süresinin Azaltılması
}

\section{Reducing Vacuum Charge Test Time Using Exploratory Data Analysis}

Tuğba Demircan Kutluay ${ }^{1}$ (1), Süleyman Eken² (1)

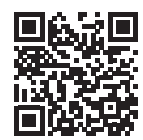

'(Yüksek lisans Öğrencisi), Kocaeli Üniversitesi, Teknoloji Fakültesi, Bilişim Sistemleri Mühendisliği, Kocaeli, Türkiye

${ }^{2}$ (Doç Dr.), Kocaeli Üniversitesi, Teknoloji Fakültesi, Bilişim Sistemleri Mühendisliği, Kocaeli, Türkiye

ORCID: T.D.K. 0000-0002-7350-6585; S.E. $0000-0001-9488-908 \mathrm{X}$

Corresponding author: Süleyman EKEN

Kocaeli Üniversitesi, Teknoloji Fakültesi, Bilişim Sistemleri Mühendisliği, Kocaeli, Türkiye

E-mail address: suleyman.eken@kocaeli.edu.tr

Submitted: 07.03 .2021

Revision Requested: 30.04 .2021

Last Revision Received: 03.05.2021

Accepted: 04.05.2021

Published Online: 29.06 .2021

Citation: Demircan Kutluay, T. ve Eken, S. (2021). Keşifsel veri analizi kullanarak vakum şarj test süresinin azaltılması.

Acta Infologica, 5(1), 187-196. https://doi.org/10.26650/acin.892586 öz

Günümüzde giderek artan rekabet koşulları ve pazarda kalıcı olabilme gibi dış faktörler firmaların sistemlerini daha verimli kullanmaya, maliyetlerini azaltmaya, yüksek kalite düzeyinde ürün üretmeye yönlendirmektedir. Firmaların yaptıkları bu çalışmalarda proses iyileştirme adımları önem taşımaktadır. Bu çalışmada üretim süreçleri keşifsel yolla analiz edilerek darboğaz oluşturan istasyon tespit edilmiştir. Keşifsel veri analizi ile kalıpları keşfetmek, anormallikleri tespit etmek, özet istatistikler ve grafik gösterimler yardımıyla varsayımları kontrol etmek için veriler üzerinde ilk araştırmaları gerçekleştirmek mümkün olmuştur. Vakum test istasyonunun katma değersiz test süresi belirlenerek proses süresi azaltılmıştır. Belirlenen yeni test süresi ile üretim kapasite artışı ve hattın daha verimli çalışması sağlanmıştır. Bu sayede günlük üretim adedi 136'dan 188'e, hat verimliliği \%55'ten \%77'ye artmış ve istasyonların birbirini beklemesi \%35'ten \%10'a düşmüştür. Aynı zamanda hattın yıllık üretim kapasitesi \%27 artarak 58K dan 79K adede ulaşmıştır.

Anahtar kelimeler: Keşifsel Veri Analizi, Grafiksel Teknik, Tanımlayıcı İstatistik, Verimlilik, Kapasite Artışı, Plant Simulation

\section{ABSTRACT}

Nowadays, external factors such as increasing levels of competition and having a permanent place in the market are directing companies to use their systems more efficiently, to reduce their costs, and to produce higher quality products. Process improvement steps are important in studies of these companies. In this study, the vacuum test station that created a bottleneck was determined by analyzing the production process in an exploratory way. Through exploratory data analysis, it was possible to perform an initial data investigation to discover patterns, spot anomalies, test hypothesis, and check assumptions with the help of summary statistics and graphic representations. By determining the value-added test time of the vacuum test station, the process time was reduced. Using the new test period, production capacity increased and a more efficient operation of the line was achieved. The number of daily production increased from 136 to 188, line efficiency increased from $55 \%$ to $77 \%$, and the stations waiting for each other decreased from $35 \%$ to $10 \%$. At the same time, the annual production capacity of the line increased by $27 \%$, reaching from $58 \mathrm{~K}$ to $79 \mathrm{~K}$.

Keywords: Exploratory Data Analysis, Graphical Technique, Descriptive Statistics, Productivity, Capacity Increase, Plant Simulation 


\section{GİRIŞ}

Keşifsel veri analizi, analitik endüstrisinde EDA olarak kısaltılan temel bir veri analizi tekniğidir ve analitik projesinin ilk aşamasında uygulanan çeşitli kavramlar ve en iyi uygulamalarla ilişkilendirilir. EDA, veri modellerini ve karşılaştırmalı veri analizini tanımlamak için grafik görselleştirme teknikleriyle ilişkili olup veri bilimi projeleri için özellik mühendisliği ve özellik seçim süreçlerinde tercih edilen bir tekniktir (Martinez vd., 2017; Sahoo vd., 2019). Yaygın olarak kullanılan EDA tekniklerinden bazıları tek değişkenli analiz, iki değişkenli analiz, çok değişkenli analiz, çubuk grafik, kutu grafiği, pasta karat, çizgi grafik, frekans tablosu, histogram ve saçılma grafiklerdir (Eken, 2020a; Eken, 2020b). EDA, makine öğrenimi modellerini tamamlayacak olan veri hazırlama aşaması için çok kullanışlıdır ve ekonomiden (Cleff, 2014) çevreye (Velleman, 1981), sağlıktan (Tummers vd., 2020) üretime (Chiarini vd., 2020) birçok alanda kullanılmıştır.

Mevcut durumda vakum test istasyonunda buzdolabına uygulanan vakum test süresi 7 dakikadır. Çevrim süresi en yüksek istasyon olan vakum test istasyonu, test süresi üretim kapasitesini belirlemekte ve dar boğaz oluşturan nokta olarak tespit edilmektedir. Dar boğaz oluşturan istasyonun test süreleri analiz edilerek optimum test süresinin kaç dakika olduğu belirlenmek istenmiştir. Bu çalışmada her bir cihaza uygulanan vakum test süreleri EDA ile incelenerek farklı modellerdeki dolabın istenen optimum basınç değerine kaçıncı sürede ulaştığı araştırılmıştır. Test süresi verileri ile yapılan analiz sonucunda vakum test süresinin azaltılması amaçlanmıştır. Takip eden paragraflarda vakum teknolojilerini içeren literatürdeki bazı çalışmalara değinilmiştir.

Öztürk vd. (2011) vakumlu soğutma teknolojisinin; yapraklı sebzelerin, mantarların, fırınlanmış ürünlerin ve pişmiş yiyeceklerin önceden soğutulmasında yaygın olarak uygulanmasını anlatmışlardır. Vakumlu soğutma, nemli ve gözenekli ürünler için hızlı bir buharlaşmalı soğutma tekniğidir. Bu çalışmanın amacı, vakumlu soğutma tekniğini semizotunun soğutulmasında uygulamak ve basınç etkisini $(0,7 \mathrm{kPa}, 1 \mathrm{kPa}, 1,5 \mathrm{kPa}$ için) soğutma süresi ve sıcaklık düşüşü üzerindeki etkisini göstermektedir. Çalışmanın diğer bir amacı, geleneksel soğutmayı (buzdolabıyla soğutma) vakumlu soğutma ile karşılaştırmaktır. Geleneksel soğutmanın, $0,7 \mathrm{kPa}$ basınçta vakumlu soğutma ile $6{ }^{\circ} \mathrm{C}$ 'lik ortam sıcaklığı ile karşılaştırılması ve vakumlu soğutmanın, semizotu için geleneksel soğutmadan yaklaşık 10 kat daha hızlı olduğunu göstermektedir. Vakumlu soğutma için kütle kaybı oranı, geleneksel soğutmaya göre daha yüksektir. Bununla birlikte vakumlu soğutma için soğutma süresi, geleneksel soğutmaya göre daha kısadır.

Rennie vd. (2000) marulun vakumla soğutulması için ürün soğutma yükü ile vakum hızı arasındaki ilişkiyi anlatmışlardır. Basınç fonksiyonunun suyun buharlaşma sıcaklığına ve vakumlu soğutucudaki basıncın düştüğü orana dayalı teorik bir ilişki geliştirilmiştir. Farklı vakum oranlarından toplanan veriler kullanılarak, sıcaklık-zaman verilerinin maksimum eğimi belirlenmiş ve maksimum ürün soğutma yükünü hesaplamak için kullanılmıştır. Vakum uygulama hızı düştüğünde gecikme azalırken vakum hızı yüksek olduğunda 1sı transfer gecikmesi olduğu görülmüştür.

Zhao vd. (2020) siklopentan yalıtımlı iki özdeş buzdolabı, biri iki yan duvarda vakum yalıtım paneli (VIP’ler) ve diğeri olmadan karşılaştırma yaparak incelemişlerdir. Bulgular VIP'lerin, daha düşük ortalama güç girişi ve daha uzun kompresör ile kapalı kalma süresi nedeniyle buzdolabının kararlı hal enerji tüketimini \% 12,4 oranında azalttığını göstermektedir. Sonuç olarak, yalnızca dondurucu bölmesi süresi artar ve taze yiyecek bölmesi sönümleme süresindeki azalmayı telafi eder. Bu da genel olarak benzer bir kompresörün açık kalma süresi ile sonuçlanır. Termal yük aktarım işleminin tam bir görünümünü elde etmek için her iki durumda da buharlaştırıcı aracılığıyla ısı transfer işleminin simülasyon sonuçları sağlanır.

Gang ve Xianping (2005) vakumlu termal izolasyon plakanın konfigürasyonunu ve kullanım özelliklerini analiz etmiş̧lerdir. BCD-186CHS tipi buzdolaplarında kullanılan vakumlu ısı izolasyon plakası ve izolasyon tabakaları dağılımı anlatılmış, ayrıca poliüretan ve bileşik ısı izolasyonu, ısı kaybı ve uygulanan bu iki malzemenin enerji tüketimi karşılaştırılmıştır. Deneysel olarak, bileşik izolasyon kullanıldığında ısı kaybının \%12,6 ve enerji tüketiminin \%11,4 oranında tasarruf sağlandığı görülmüştür. Bu çalışmada, uygulama modları, uyarıları ve vakumlu 1sıl yalıtım levhasının buzdolabına etkisi ortaya koyulmuştur. Vakumlu ısıl yalıtım levhası olasılığı açıklanmıştır.

Tao vd. (2004) vitrinli buzdolabının enerji verimliliğine ilişkin her zamankinden daha katı düzenlemelere yanıt olarak enerji kullanımını en aza indirmek için bir prototip tasarlamıştır. VIP’ler ve vakumlu cam (VG) kullanılarak yalıtım iyileştirmeleri 
gibi seçenekler, vitrinli buzdolabında ısı kaybı ölçülerek incelenmiştir. Sonuçlar, vitrinli buzdolabına VG ve VIP’lerin aynı anda monte edilmesiyle enerji verimliliğinin \%30’a kadar artırılabileceğini göstermektedir.

Chen vd. (2010) harici ısı transferli vakumlu termiyonik buzdolabı modeli incelenmiştir. Soğutma yükü ve performans katsayısı (COP) için genel ifadeler, sonlu zaman termodinamiği ve dengesiz termodinamiğin kombinasyonu kullanarak türetmişlerdir. Optimum soğutma yükü ve COP bölgeleri ile ısı rezervuar sıcaklığının cihazın optimum performansına etkisi detaylı sayısal örneklerle analiz edilmiştir. İş fonksiyonunun termiyonik cihazın soğutma yükü ve COP performansları üzerindeki etkileri de incelenmiştir. Burada elde edilen sonuçlar, harici ısı transferini dikkate almadan geleneksel analiz kullananlarla karşılaştırıldığında mevcut analizin gerçek vakumlu termiyonik cihazlar için daha pratik olduğu gösterilmiştir. Sonuçlar, pratik termiyonik buzdolaplarının tasarımı ve uygulaması için kılavuzlar sağlayabilecek şekilde açıklanmıştır.

Misra vd. (2013) mikroskobun, kanal yoğunluğu haritalarını alabilen ve seyreltik buzdolabı sıcaklıklarında ve yüksek (14 T) manyetik alanlarda atom altı uzaysal çözünürlük durumlarında uygulanabilen bir tarama formundaki yapısı ve performansını anlatmışlardır. Tamamen ultra yüksek vakum sistemi, alttan yüklemeli seyreltme buzdolabının sonunda iki numune mikroskobu aşamasına görsel erişim sağlar ve yerinde uçların ve numunelerin transferini kolaylaştırır. İki numuneli aşamanın incelenen numunenin en iyi alanını sağladığı ve testin ömrünü uzattığı görülmüştür. Ayrıntılı olarak anlatılan mikroskobun başarılı termal ankrajı, $250 \mathrm{mK}$ 'lı ölçülen elektron sıcaklı̆̆ ile $20 \mathrm{mK}$ 'lik bir temel sıcaklık okuması ile doğrulanmıştır. Tamamlayıcı titreşim ölçümleri ile birlikte atomik olarak çözülmüş görüntüler, bu cihazdaki titreşim izolasyon şemasının etkinliğini doğrulamıştır. Son olarak mikroskobun, uygulanan bir manyetik alanda hem sıfır alanında hem de taban sıcaklığında spektroskopik haritaları ölçülerek daha fazla soğutmalı tipik makinelerle aynı seviyede performans gösterebileceği açıklanmaktadır.

Sukumar vd. (2015) çalışmalarında günümüz soğutma ve iklimlendirme sistemlerinin insanlar için gerekli hale geldiği ve soğutma sistemlerinin soğutma etkilerini sağlamak için farklı soğutucu akışkanların kullanıldığını belirtmişlerdir. Dolaylı olarak bu soğutucular çevreye zararlı gazlar yayarak birçok etkiye neden olurlar. Kloroflorokarbon gibi gazların atmosfer ve ozon tabakası üzerindeki etkileri incelenmiştir. Bu nedenle çevre dostu soğutma sistemlerine ihtiyaç duyuldu. Geleneksel soğutma sistemlerinin neden olduğu kirlilik, buhar jetli soğutma sisteminin ve mevcut sistemin çalışmasını etkilemiştir. Bu nedenle vakum pompası flaş odası ve flaş odası içerisindeki toplam hava ile çıkarılabilir bir vakum sisteminin oluşturulduğu açıklanmıştır. Vakum sistemi sayesinde su, gizli ısıyı kendisinden alarak kaynama noktasını düşürdüğünde su buharlaşmaya başlar. Burada su düşük sıcaklıklara kadar soğutulur ve bu soğumuş suyun iklimlendirme için kullanılması anlatılır.

Thiessen vd. (2016) buzdolabının termodinamik davranışı deneysel olarak incelenmişlerdir. Buzdolabı içerisindeki vakum yalıtım paneli (VIP) kapsama alanı değiştirilerek kabinin etrafına yerleştirilmiştir. Çalışmalar sonunda farklı VIP düzenlemeleri ile aynı buzdolabı modelinden 16 örnek oluşturulmuş ve kapsamlı ters ısı kaçağı (RHL) ve enerji tüketimi testleri uygulanmıştır. Gözlenen sonuçlarla enerji tüketiminin hem kapsama alanına hem de konuma bağlı olduğu belirtildi. Toplanan veriler statik olarak analiz edilerek panellerin montajı için en uygun alanların belirlenmesi sağlanır. Kapılara ve arka duvara sırasıyla \%6 ve \%11 enerji tasarruflu paneller monte edilmiştir. Genel enerji tüketim analizinde VIP panellerin \%56 kapsama alanının enerji tüketimini \%21 azalttığı görülmüştür.

Buzdolabının soğutma çevriminde kullanılan elemanlar; kondansatör, çerçeve 1sıtıcısı, arka duvar 1sıtıcısı, kurutucu, stop valf, manyetik valf, kılcal boru, eşanjör ve kompresördür. Kompresör, kılcal boru içerisinde basınç farkı yaratmayı sağlar. Kompresörün içinde nem kaçağı olmaması amacıyla basınçlı azot bulunmaktadır (Şekil 1'e bakınız). Kompresörün içerisindeki nem kaçağını önlemek için kompresör ucundaki bakır kılcal boruya valf takılarak vakumlama işlemi yapılır. Mevcut çalışma Fridge ve Freezer iki soğutma kompartımanına sahip buzdolaplarının kompresöre uygulanan vakum test süresinin azaltma çalışmasını kapsamaktadır. 


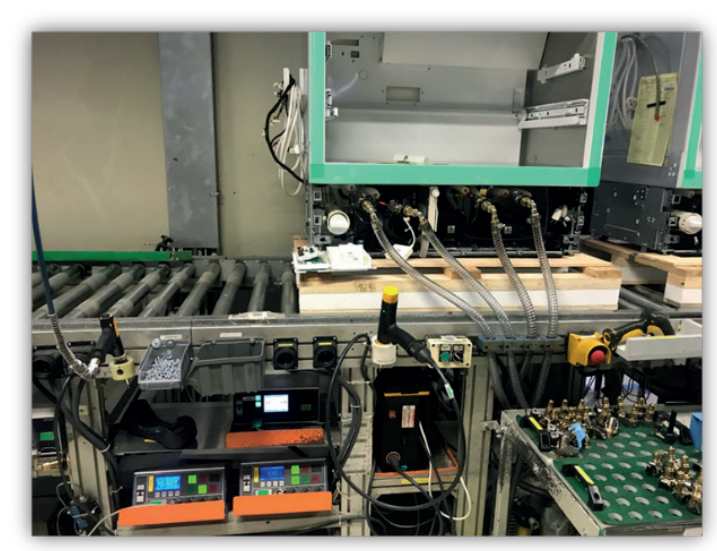

(a)

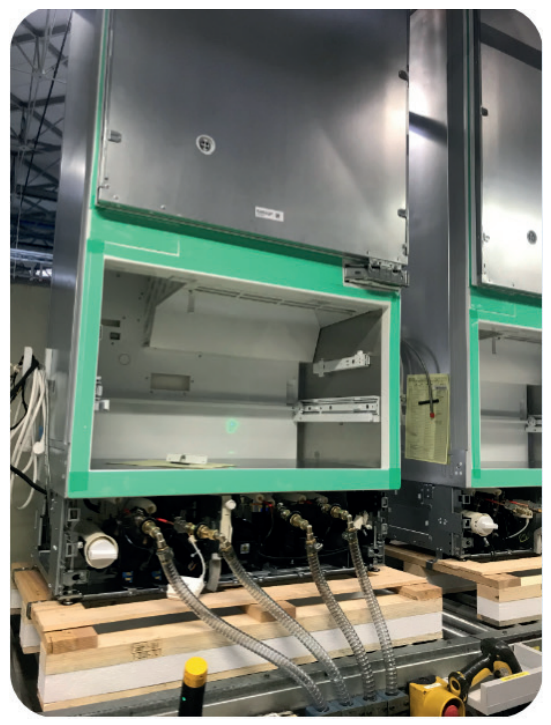

(b)

Şekil 1. Vakum şarj test cihazı (a) genel görünüm (b) daha yakın bir görünüm

Vakum test süresinin azaltılması ile vakum test istasyonun bir vardiyada test edebileceği maksimum dolap sayısı arttırılarak vardiyalık üretim kapasite artışının sağlanması amaçlanacaktır. Elde edilen analiz sonucu ile belirlenen yeni vakum test süresine göre vardiyalık test edilen toplam cihaz sayısı, Plant Simulation ${ }^{1}$ programı ile simüle edilerek hesaplanmıştır. Yeni test süreleri ile simülasyonda belirlenen vardiyalık toplam cihaz sayısı, hattın üretebileceği maksimum adet sayısını belirleyecektir. Çalışmanın geri kalanı şu şekilde organize edilmiştir: 2. bölümde elde edilen veriseti hakkında bilgi verilmiş, kullanılan yöntemler ve verimlilik çıktıları sunulmuştur. 3. bölümde ise tartışmalara, sonuçlara ve gelecek çalışmalara yer verilmiştir.

\section{MALZEME VE YÖNTEMLER}

\subsection{Veriseti}

Veriseti, buzdolaplarının 12760 vakum testi verilerini içermektedir. Test verilerine ait bilgiler tarih, saat, cihaz modeli, hangi kompartımana ait olduğu, cihazın sıcaklığı, kılcal borudaki basınç değeri ve ortam koşuluna ait bilgileri içermektedir. Model sütunu inç bazlı Miele, Thermador, Gagganeu, Bosch, Siemens markalarını içermektedir. Ortam koşulu olarak yaz, kış mevsimi ve bakım öncesi, bakım sonrası test verileri değerlendirilmiştir. Şekil 2'de Gagganeu markasına ait bir test sonucunu yansitan ölçüm bilgileri gösterilmiştir.

\subsection{Vakum Şarj Test Süreleri için EDA}

Bu kısımda, veri setinde hangi cihaz modellerinden ne kadar var olduğu, yaz ve kış mevsimleri bazında vakum şarj test sürelerinin araştırılması gerçeklenmiştir. Vakum testlerinin analiz sonucuna göre hedeflenen 0,06 bar basınç değerine Şekil 3’te de belirtildiği gibi 0-5 dakika arasında ulaşıldığı tespit edilmiş̧ir. Yaz ayına ait bir test verisinin sadece 5. dakikanın üzerinde istenilen bar değerine ulaştı̆̆ görülmüş ve bu veri sıra dışı durum olarak değerlendirilmiştir. Sonuç olarak maksimum vakum test süresi de 5 dakika olarak belirlenmiştir. Şekil 4 ise yaz ve kış aylarında 0,06 bar değerine kaç adet cihazın kaçıncı dakikada ulaştığını göstermektedir.

1 https://www.dex.siemens.com/plm/tecnomatix/plant-simulation 


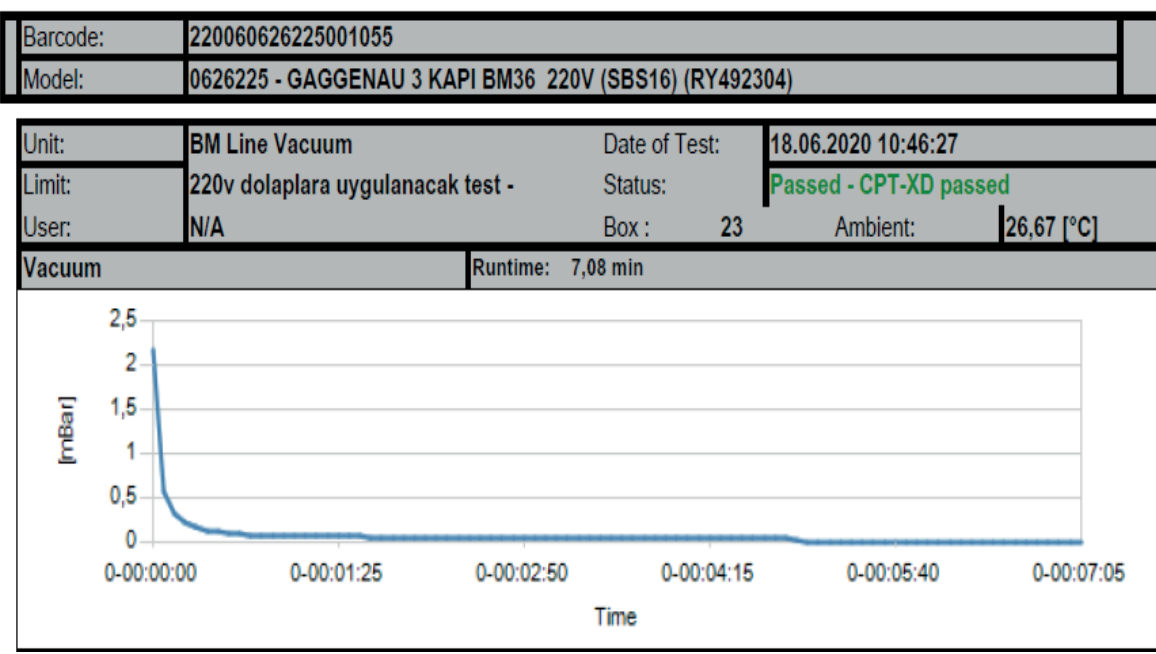

Şekil 2. Gagganeu için test sonuçları

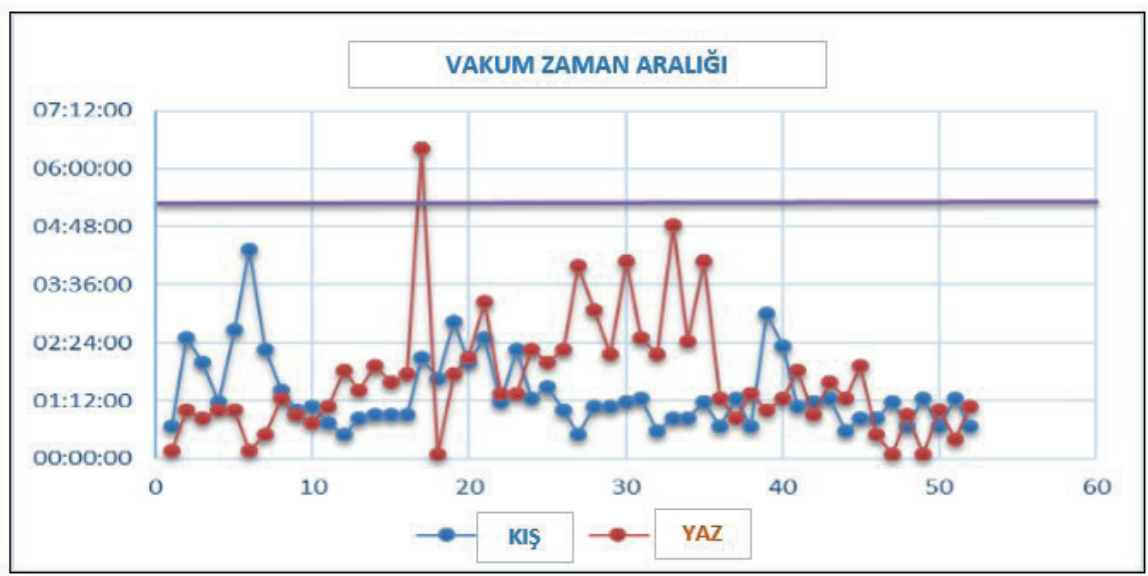

Şekil 3. 0,06 bar değerine göre zaman aralığı

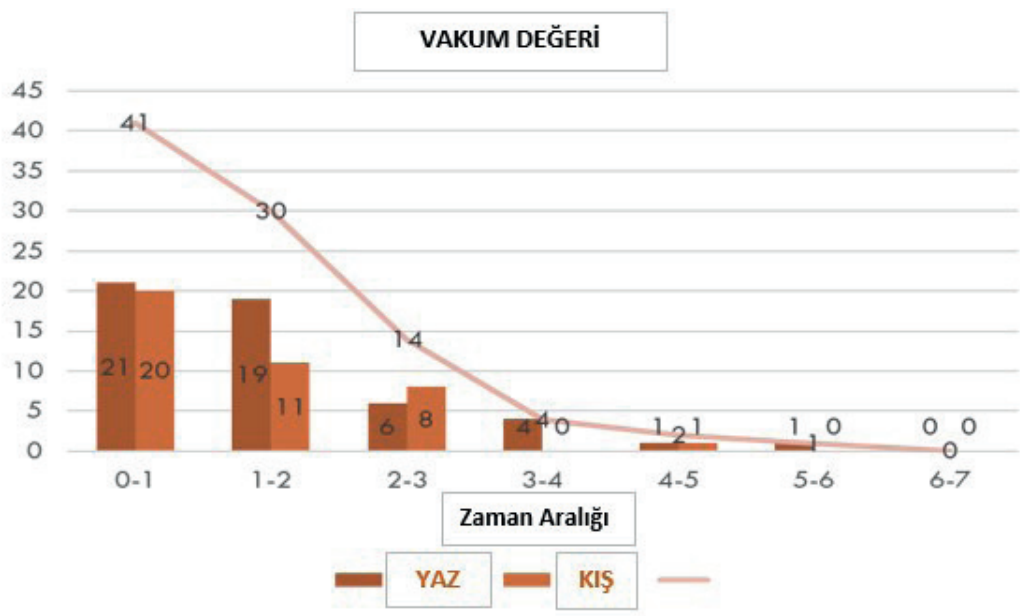

Şekil 4. Vakum zaman aralığına göre 0,06 bar için toplam cihaz sayısı 
Python programı kullanılarak yapılan vakum test süreleri EDA çalışmasına göre, yeni test süresi 5 dakika olarak belirlenmiştir. Buzdolabı cihazlarına 5 dakika vakum test süresi uygulandığı durumda test sonuçlarındaki değişim Şekil 5’te gösterilmiştir. Verisetine ve analiz dosyalarına şu linkten erişilebilmektedir:

https:/github.com/suleymaneken Vacuum-Charge-Test-with-EDA

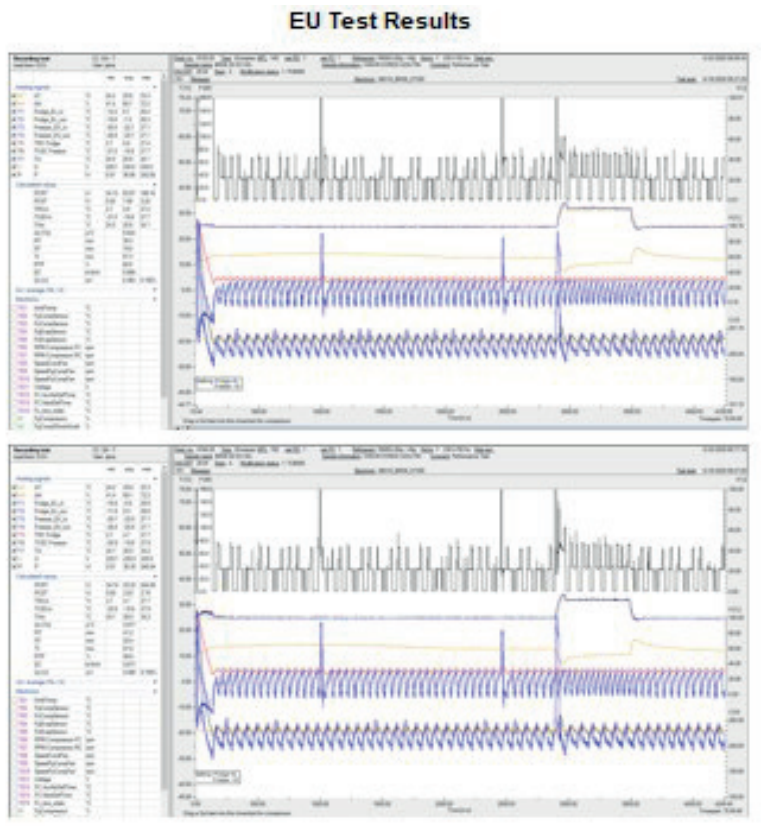

(a)

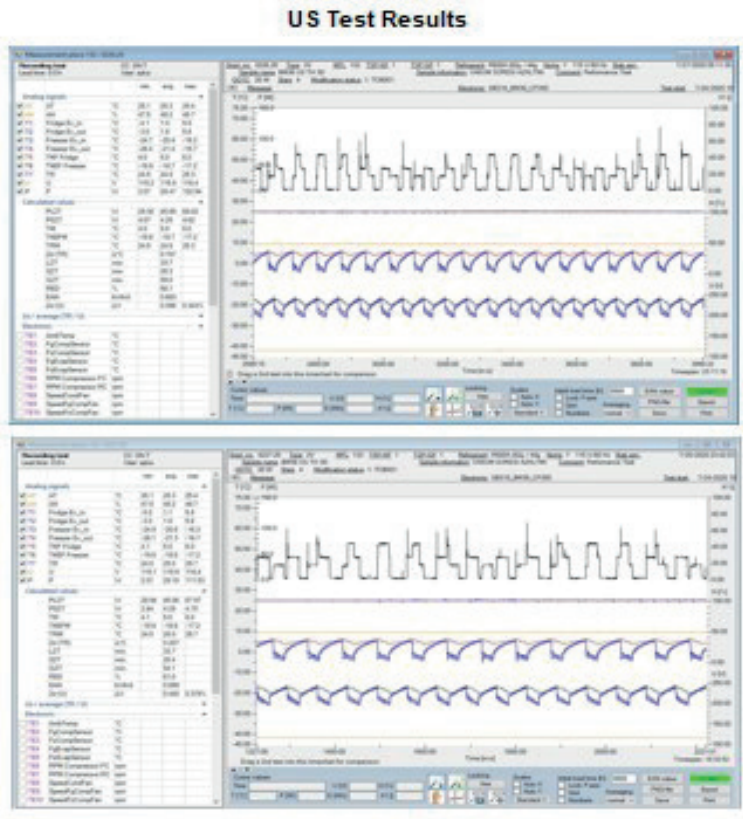

(b)

Şekil 5. (a) EU modeli (b) US modeli için 5 dakika test uygulama sonuçları

\subsection{Plant Simulation ile Vardiya Verimlilik Analizi}

Yeni test süresinin, 5 dakika olarak belirlenmesi ile vardiyalık üretim adedinin Şekil 6'da görüldüğü Plant Simulation programı kullanılarak simüle edildiğinde 68'den 94'e çıktı̆̆ı gözlemlenmiştir.

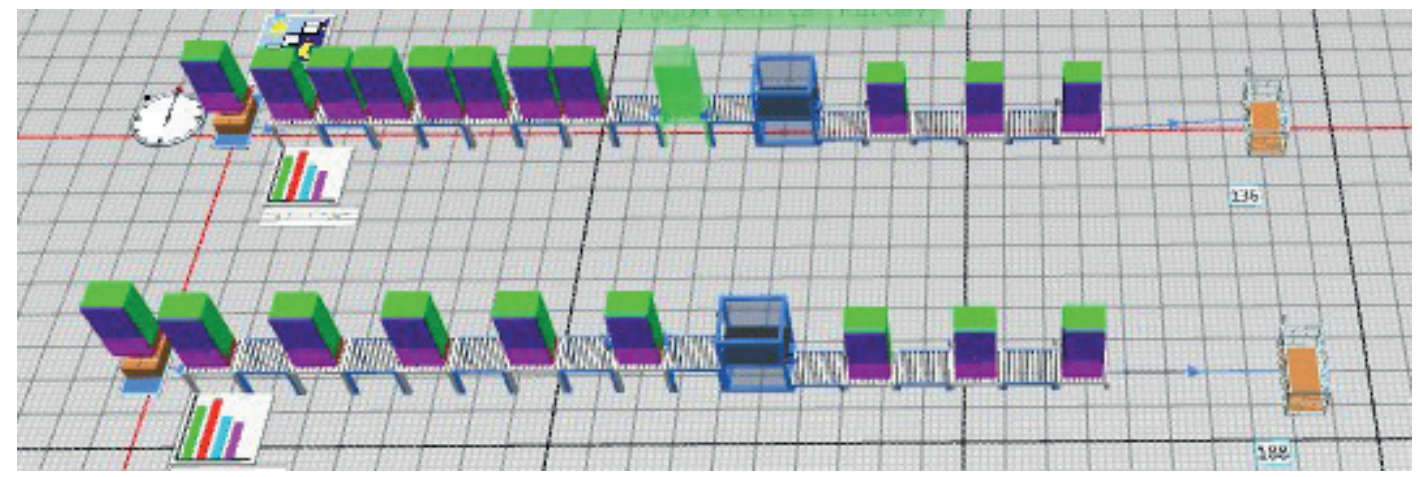

Şekil 6. Plant Simulation programı uygulama görseli

Vardiyalık üretim adetinin 94'e çıkması ile istasyonların birbirini beklemesi ve bloke etme durumunun azalması ile hat içi istasyon çalışma verimliliği arttırılmıştır. Şekil 7'de simülasyon görselinde ve grafikte hat içi istasyon verimliliğindeki değişim anlatılmıştır. Şekil 8'de görüldüğü gibi günlük üretim adedi 136'dan 188'e, hat verimliliği \%55'ten \%77'ye artmış ve istasyonların birbirini beklemesi \%35’ten \%10’a düşmüştür. Aynı zamanda hattın yıllık üretim kapasitesi \%27 artarak $58 \mathrm{~K}$ dan $79 \mathrm{~K}$ adede ulaşmıştır. 


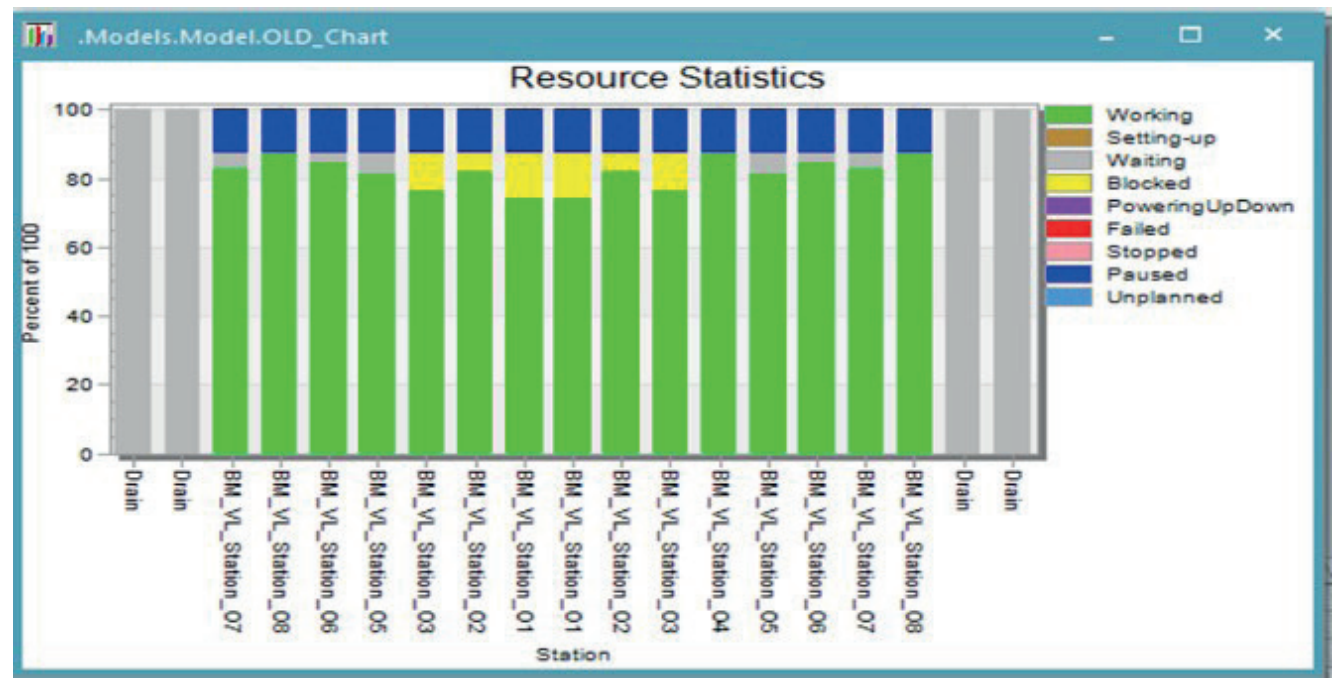

Şekil 7. Plant Simulation programı kaynak istatistiği

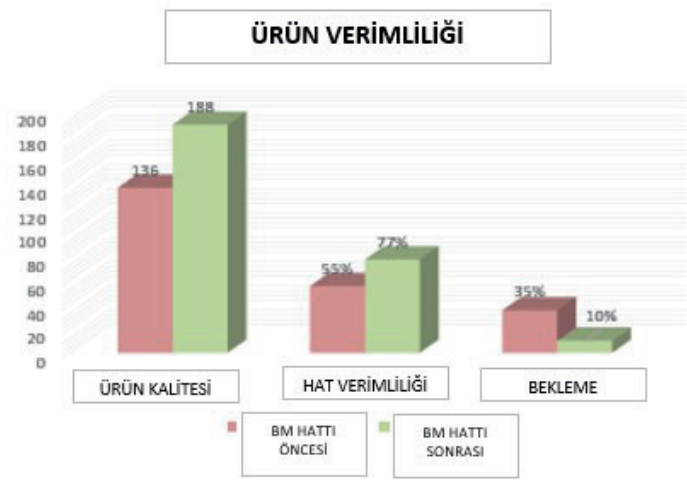

(a)

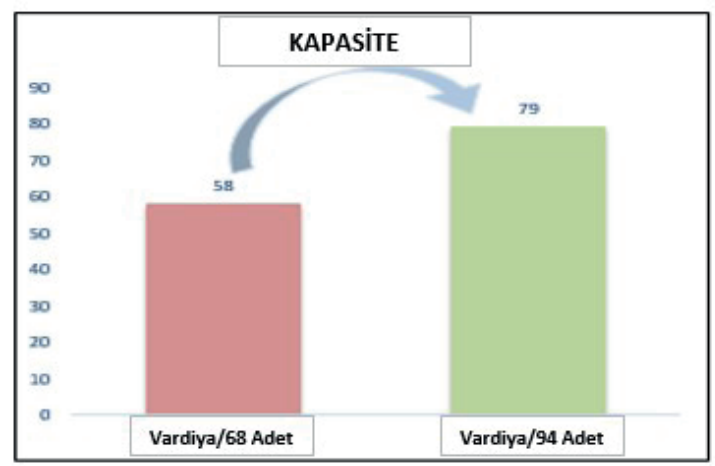

(b)

Şekil 8. Değişim grafikleri (a) ürün verimlilik (b) kapasite

\section{TARTIŞMA VE SONUÇLAR}

EDA, bir veri setine ilişkin içgörüyü en üst düzeye çıkarmak, altta yatan yapıyı ortaya çıkarmak, önemli değişkenleri çıkarmak, aykırı değerleri ve anormallikleri tespit etmek, temel varsayımları test etmek, açgözlü modeller geliştirmek ve optimum faktör ayarlarını belirlek için çeşitli teknikler (çoğunlukla grafiksel) kullanan bir veri analizi yaklaşımı ve felsefesidir. $\mathrm{Bu}$ çalışmada yaygın olarak kullanılan EDA tekniklerinden çizgi grafik, histogram, ve özet istatistik (tanımlayııı) bilgisinden yararlanılmıştır. Kaçıncı saniyede kılcal borudaki basınç değeri istenilen basınç değerine ulaşıldığının takibi yapılmıştır. $\mathrm{Bu}$ çalışmada EDA yöntemleri kullanılarak vakum test süresi azaltılmış, hattın daha verimli çalışması sağlanmış ve üretim kapasitesi arttırılmıştır. Vakum süresi azaltılmasaydı hattın talep edilen adette üretim yapabilmesi için 24K€ değerinde yatırım yapılarak ek bir istasyon kurulması ile sağlanacaktı. Bu çalışma sayesinde 24K€ yatırım yapılmadan hedeflenen üretim adedine ulaşılmıştır.

Tablo l'de ise farklı kriterler altında önerilen çalışmanın diğer çalışmalarla karşılaştırılması verilmiştir. Enerji tüketimi açısından incelendiğinde önerilen çalışma enerji tüketimine odaklanmamıştır. Vakum şarj test süresini optimize ederek ürün verimliliği ve kapasiteye odaklanılmıştır. Dolayısıyla vakum test zamanında bir iyileşme ile odak sağlanmıştır. Vakum yalıtım paneli kullanım yüzeyi çalışmada yan, alt ve üst panellere yerleştirilmiş olup çevresi tamamen kapama veya sadece yan duvar panellerine yerleştirmenin vakum şarj süresine etkisi bakılmamıştır. Bu da test ortamındaki VIP kullanım yüzeyinin standart oluşundan kaynaklanmaktadır. Kompartıman olarak buzdolabı ve dondurucu kısmı ele alınmıştır. Isı kaybı ve kompresör eşanjör kaynak tipi açısından diğer çalışmalarla benzerlik göstermektedir. 
Tablo 1

Farklı kriterler altında önerilen çalışmanın diğer çalışmalarla karşılaştırılması

\begin{tabular}{|c|c|c|c|}
\hline Karşılaştırma kriteri & Önerilen çalışma & Thiessen vd. (2016) & Zhao vd. (2020) \\
\hline Enerji tüketimi & Değişmedi & $\% 21$ azaltıld $_{1}$ & $\% 12,4$ azaltıld $_{1}$ \\
\hline $\begin{array}{l}\text { Vakum yalıtım paneli (VIP) } \\
\text { kullanım yüzeyi }\end{array}$ & $\begin{array}{l}\text { Yan, alt ve üst panellere } \\
\text { yerleştirilmiş }\end{array}$ & Kabinin etrafına yerleştirilmiş & Yan duvar panellerine yerleştirilmiş \\
\hline Vakum test zamanı & 7 dk'dan 5 dk'ya düşürüldü & Değişmedi & Değişmedi \\
\hline İncelenen soğutma bölmesi & Buzdolabı ve dondurucu bölmeleri & $\begin{array}{l}\text { Buzdolab1, dondurucu ve tam esnek } \\
\text { bölmeleri }\end{array}$ & Buzdolabı ve dondurucu bölmeleri \\
\hline Is1 kayb1 & Azaltıldı & Azaltıld 1 & Azaltıld 1 \\
\hline Kompresör ve eşanjör kaynak tipi & Lokring kaynak & Gaz altı kaynak & Lokring kaynak \\
\hline
\end{tabular}

Çalışmanın iyileştirilme adımlarında ise hatta devam eden \%10'luk beklemenin sebebi araştırılacak ve hat içi \%27'lik verimlilik kaybının nedenleri sorgulanacaktır. Böylece ürün verimliliği ve kapasitenin daha da artması beklenmektedir.

Hakem Değerlendirmesi: Dıș bağımsız.

Çıkar Çatışması: Yazarlar çıkar çatışması bildirmemiştir.

Finansal Destek: Yazarlar bu çalıșma için finansal destek almadığını beyan etmiștir.

Yazar Katkıları: Çalışma Konsepti/Tasarım- T.D.K.; Veri Toplama- T.D.K., S.E.; Veri Analizi/Yorumlama- T.D.K., S.E.; Yazı Taslağı- T.D.K., S.E.; İçeriğin Eleştirel İncelemesiS.E.; Son Onay ve Sorumluluk- T.D.K., S.E.

Teşekkür: BSH Ev Aletleri Sanayi ve Ticaret A.Ş.'ye çalışmanın yapılmasındaki katkılarından dolayı teşekkür ederiz.

Peer-review: Externally peer-reviewed.

Conflict of Interest: The authors have no conflict of interest to declare.

Grant Support: The authors declared that this study has received no financial support.

Author Contributions: Conception/Design of Study- T.D.K.; Data Acquisition- T.D.K., S.E.; Data Analysis/Interpretation- T.D.K., S.E.; Drafting Manuscript- T.D.K., S.E.; Critical Revision of Manuscript- S.E.;Final Approval and Accountability- T.D.K., S.E.

Acknowledgement: We thank BSH Turkey for their contribution to the study.

\section{Kaynaklar/References}

Chen, L., Ding, Z., \& Sun, F. (2010). Performance analysis of a vacuum thermionic refrigerator with external heat transfer. Journal of applied physics, 107(10), 104507.

Chiarini, A., Belvedere, V., \& Grando, A. (2020). Industry 4.0 strategies and technological developments. An exploratory research from Italian manufacturing companies. Production Planning \& Control, 31(16), 1385-1398.

Cleff, T. (2014). Exploratory data analysis in business and economics. Exploratory Data Analysis in Business and Economics. https://doi. org/10.1007/978-3-319-01517-0.

Eken, S. (2020a). An exploratory teaching program in big data analysis for undergraduate students. Journal of Ambient Intelligence and Humanized Computing, 11(10), 4285-4304.

Eken, S. (2020b). Büyük Verinin İnteraktif Görselleştirilmesi: Tableau Üzerine Öğrenci Deneyimleri. Avrupa Bilim ve Teknoloji Dergisi, (18), $262-271$.

Gang, L., \& Xianping, Z. (2005). Research on vacuum thermal isolation plate applied to refrigerator for isolation. Cryogenics and Superconductivity, 4.

Misra, S., Zhou, B. B., Drozdov, I. K., Seo, J., Urban, L., Gyenis, A., ... \& Yazdani, A. (2013). Design and performance of an ultra-high vacuum scanning tunneling microscope operating at dilution refrigerator temperatures and high magnetic fields. Review of Scientific Instruments, 84(10), 103903.

Martinez, W. L., Martinez, A. R., \& Solka, J. (2017). Exploratory data analysis with MATLAB. Florida, FL:Crc Press.

Ozturk, H. M., Ozturk, H. K., \& Kocar, G. (2011). Comparison of vacuum cooling with conventional cooling for purslane. International Journal of Food Engineering, 7(6), 1-18.

Rennie, T. J., Raghavan, G. S. V., \& Vigneault, C. (2000). Determination of the product refrigeration load in vacuum cooling of lettuce. Applied Engineering in Agriculture, 16(5), 459.

Sahoo, K., Samal, A. K., Pramanik, J., \& Pani, S. K. (2019). Exploratory data analysis using Python. International Journal of Innovative Technology and Exploring Engineering (IJITEE), 8(12), 2019.

Sukumar, R. S., Gopichand, A., Janardhana, U., Kumar, V. S., \& Chanti, B. V. Design and Fabrication of Water Refrigeration System by Creating Vacuum. International Journal of Innovative Research in Science, Engineering and Technology, 4(4), 2428-2434.

Tao, W. H., Huang, C. M., Hsu, C. L., \& Lin, J. Y. (2004). Performance study of an energy-efficient display case refrigerator. Chemical Engineering Communications, 191(4), 550-565.

Thiessen, S., Knabben, F. T., \& Melo, C. (2016). An Experimental Study on the Use of Vaccum Insulation Panels in Household Refrigerators. Proceedings of International Refrigeration and Air Conditioning Conference (pp. 1-8). West Lafayette, IN: Purdue University. 
Tummers, J., Catal, C., Tobi, H., Tekinerdogan, B., \& Leusink, G. (2020). Coronaviruses and people with intellectual disability: an exploratory data analysis. Journal of Intellectual Disability Research, 64(7), 475-481.

Velleman, P. F., \& Hoaglin, D. C. (1981). Applications, basics, and computing of exploratory data analysis. London, Duxbury Press.

Zhao, R., Qiao, L., Gao, Z., \& Huang, D. (2020). Effect of Vacuum Insulation Panels on Energy Consumption and Thermal Load Transfer between Compartments in a Three-Temperature Frost-Free Refrigerator. Energies, 13(7), 1559. 
